\title{
Labour market information and the choice of vocational specialization
}

Citation for published version (APA):

Borghans, L., de Grip, A., \& Heijke, J. A. M. (1990). Labour market information and the choice of vocational specialization. Researchcentrum voor Onderwijs en Arbeidsmarkt, Faculteit der Economische Wetenschappen. ROA Working Papers No. 2E https://doi.org/10.26481/umarow.199002E

Document status and date:

Published: 01/01/1990

DOI:

10.26481/umarow.199002E

Document Version:

Publisher's PDF, also known as Version of record

\section{Please check the document version of this publication:}

- A submitted manuscript is the version of the article upon submission and before peer-review. There can be important differences between the submitted version and the official published version of record.

People interested in the research are advised to contact the author for the final version of the publication, or visit the DOI to the publisher's website.

- The final author version and the galley proof are versions of the publication after peer review.

- The final published version features the final layout of the paper including the volume, issue and page numbers.

Link to publication

\footnotetext{
General rights rights.

- You may freely distribute the URL identifying the publication in the public portal. please follow below link for the End User Agreement:

www.umlib.nl/taverne-license

Take down policy

If you believe that this document breaches copyright please contact us at:

repository@maastrichtuniversity.nl

providing details and we will investigate your claim.
}

Copyright and moral rights for the publications made accessible in the public portal are retained by the authors and/or other copyright owners and it is a condition of accessing publications that users recognise and abide by the legal requirements associated with these

- Users may download and print one copy of any publication from the public portal for the purpose of private study or research.

- You may not further distribute the material or use it for any profit-making activity or commercial gain

If the publication is distributed under the terms of Article $25 \mathrm{fa}$ of the Dutch Copyright Act, indicated by the "Taverne" license above, 


\section{LABOUR MARKET INFORMATION AND THE CHOICE OF VOCATIONAL SPECIALISATION}

ROA-W-1990/2E

Lex Borghans, Andries de Grip and

Hans Heijke

A case study of the Dutch Junior Secondary Technical Education

RESEARCH CENTRE FOR EDUCATION AND LABOUR MARKET

Faculty of Economic Sciences

Rijksuniversiteit Limburg

Maastricht, April 1990 
CIP-GEGEVENS KONINKLIJKE BIBLIOTHEEK, DEN HAAG

Borghans, Lex

Labour market information and the choice of vocational specialisation: a case study of the Dutch Junior Secondary Technical Education / Lex Borghans, Andries de Grip and Hans Heijke. - Maastricht : Research Centre for Education and Labour Market, Faculty of Economic Sciences, Rijksuniversiteit Limburg. - (Report / Research Centre for Education and Labour Market, ISSN 0922-8098; 1990/2E) Met 1it. opg. ISBN $90-5321-030-X$ in spiraalband SISO 318.7 UDC $331.5+377.3:: 62(492)$

Trefw.: lager technisch onderwijs en arbeidsmarkt; Nederland; onderzoek. 
CONTENTS

ABSTRACT

1. INTRODUCTION 1

2. THE PROBLEM OF INFORMATION 4

3. STUDENTS' EXPECTATIONS 9

4. THE ESTIMATION 11

5. ESTIMATION RESULTS 14

6. IMPLICATIONS 20

7. CONCLUSIONS 24

APPENDIX: THE DATA 25

$\begin{array}{lr}\text { REFERENCES } & 29\end{array}$ 
ABSTRACT

The choice of a vocational specialisation at school is often hampered by the need of labour market information which is not available. This paper investigates whether the situation on the labour market influences the choices of students of the Dutch junior secondary technical schools and whether they anticipate future labour market situations. We try to answer this question by introducing two extreme models: the cobweb model and the rational expectations model. Both models have been estimated and a comparison has been made by means of an encompassing experiment. Finally, by using the estimation results the extent of the information problem has been measured. 


\section{INTRODUCTION}

The decision to invest in human capital is a very difficult question. Human capital theory simply assumes that students have complete information, but in actual practice this is obviously much more complicated. From the human capital point of view prices enclose all relevant information, apart from individual preferences. Wages reflect everything that is needed for the individual decision whether or not to invest.

In the real world, however, students face two big problems in their decision to invest in their human capital. The first difficulty is the absence of wages that reflect the value of their schooling at the moment they will enter the labour market. Wages that can be observed are present wages for present labour. These present wages will certainly be an indication for future wages, but this information will nevertheless not be perfect. Lack of information may lead to imperfect anticipation. The most extreme version of this vision is the so-called 'cobweb-theory' in which no anticipation takes place at all.

A second difficulty arises because the labour market is not, as assumed by the neo-classical theory, completely cleared by wages. And because of this 'imperfection', the argument that all relevant information is reflected in the wages does not hold anymore. Thus, students need more information than merely wages to decide how to invest in their human capital.

The aim of this paper is to investigate, empirically, the use of information by students. In this study the attention is focussed on the Dutch junior secondary technical education1. The reason to choose this type of education is twofold. Firstly, the junior secondary technical education is a vocational school. For that reason we expect the specialisations that can be chosen to be closely connected with specific labour market segments. This implies that the decision to specialise is a crucial moment in the course. By specialising, a student excludes the alternative specialisations. It is obvious that in this kind of situation the information problem is very important.

1. In the Netherlands these schools are called LTS (Lower Technical School) and ITO (Individual Technical Education). 
A second reason to focus on junior secondary technical education is the fact that in The Netherlands a compulsory school attendance exists for children below the age of 17. Mostly, children visit this type of technical schools from 12 till 16, so the only choices they can make are the specialisations, as not going to school is no alternative.

To investigate the information problem, two questions will be raised in this paper. The first question is: does the labour market situation play a role in the choice of a vocational specialisation? As noticed above, in a world in which markets are not cleared completely by wages, also other aspects (e.g. changing working conditions) might influence the allocation process. In this study only two aspects will be taken into account: the wages and the probability to get a job. In other words, the question is whether wages and unemployment in a certain market segment provide signals for students about the perspectives of jobs, which regulate the coordination between demand and supply.

In the economic literature several studies have been devoted to this subject, although most of them relate students' choices only to (1ifetime) wages, e.g. Freeman (1975) and Siow (1984). Freeman (1980), however, relates the enroliment to the employment opportunities.

If students react to the signal provided by the labour market situation, the second question arises: do students anticipate future labour market situations or do they only take the present situation as a signal for the future? The courses they follow will take some years, so in order to get an optimal allocation students should collect additional information to anticipate future labour market situation.

This question is mostly solved by assumption. Freeman (1975, 1980) presumes a cobweb model, while Siow (1984) and Zarkin (1985) presume a rational expectations model in which anticipations are optimal. Zarkin (1983) discusses the distinction between the two alternatives, cobweb and rational expectations, but his choice for the latter is not grounded empirically.

The organisation of this paper is as follows. In the second section the information problem will be analysed and a model will be formulated which describes the choice problem. The role of expectations in this model will be analysed in the third section. Section 4 deals with the estimation procedure 
and section 5 provides the estimation results. In the sixth section some implications of these results will be investigated. Finally some conclusions are drawn. 


\section{THE PROBLEM OF INFORMATION}

At the Dutch junior secondary technical schools students start with a general curriculum of one (until 1970) or two (from 1971) years. After this general course they have to make a choice of one of the (two year) vocational specialisations the school offers.

The economic point of view of this type of choice problem is that students will choose that specialisation that will make them best off. That is, if we assume a utility-function to exist, students will choose the alternative which delivers the greatest utility. This utility will be influenced by the contents of the study (consumption effect) and improvements in the labour market position (investment effect). Thus, students have to calculate all these effects in order to evaluate their utility function.

It is, of course, impossible to make such complex calculations. Hayek (1945) stresses this impossibility: 'There is hardly anything that happens anywhere in the world that might not have an effect on the decision he ought to make'2. There are so many influences upon the utility that it is impossible to evaluate them all. But from Hayek's point of view all relevant information will, nevertheless, reach the decision maker: 'We must look at the price system as such a mechanism for communicating information ...3. Because of the market system all relevant information, except for individual preferences, will be reflected in the price.

This means that except for individual preferences, the choice between the specialisations would be determined by the prices, i.e. the wages (and the direct costs of the human capital investment). The main assumption of Hayek's story, however, is the existence of a perfect market and this assumption does not hold in the case of students' choices.

There are two main factors that violate the perfect market assumption. The first factor is the fact that the labour market is not completely cleared by wages. In order to make wages reflect all relevant information it is necessary that the markets are cleared by them. There are, however, other signals that also play a part in the allocation process, for example the

2. Hayek (1945), p. 525.

3. Hayek (1945), p. 526 . 
unemployment and qualitative adjustments of the job characteristics. In order to study the choice behavior of students these factors should also be brought into the analysis.

The second factor that violates Hayek's assumption is the fact that the equilibrium prices that contain all relevant information in fact do not exist. The only wages that can be observed are current wages, but these are not what students are looking for. The wages that are relevant for their decisions are the future wages, the wages prevailing during their working lifes, and especially the wages in the year in which they enter the labour market. But for these future wages no market exists.

The only way left to overcome this problem is to form an expectation of these future wages. But, consequently, the information problem reappears in this calculation of expectations. In this imperfect situation choices will be based on expectations rather than prices and not only the wages will be a relevant factor. The aim of this paper is to investigate whether the choice for a specialisation at the junior secondary technical schools can be explained by these factors.

In this analysis, the specialisations are clustered into three groups in order to integrate corresponding segments of the labour market and to avoid problems due to changing classification schemes through time at a lower level of aggregation. These three specialisations are: building industry $(B)$, metal industry (M) and food and catering industry (F) ${ }^{4}$. Figure I shows the development of the numbers of students choosing for one of these three specialisations. The figure clearly shows that not only the total number of students has changed through time, but also that the distribution among the three specialisations is far from constant.

These changing choices might, apart from changes in capabilities and the students' preferences, be explained by changes in the situation of the labour market segments that these specialisations give access to. The basic assumption of this study is that students choose a specialisation by taking into account their preferences and the labour market perspectives of vocational specialisations. The distribution of preferences among students is not expected to change quickly, while the labour market situation might change fast.

4. Details about the data can be found in the appendix. 
Figure I: The enrollment through time in the three specialisations ${ }^{5}$

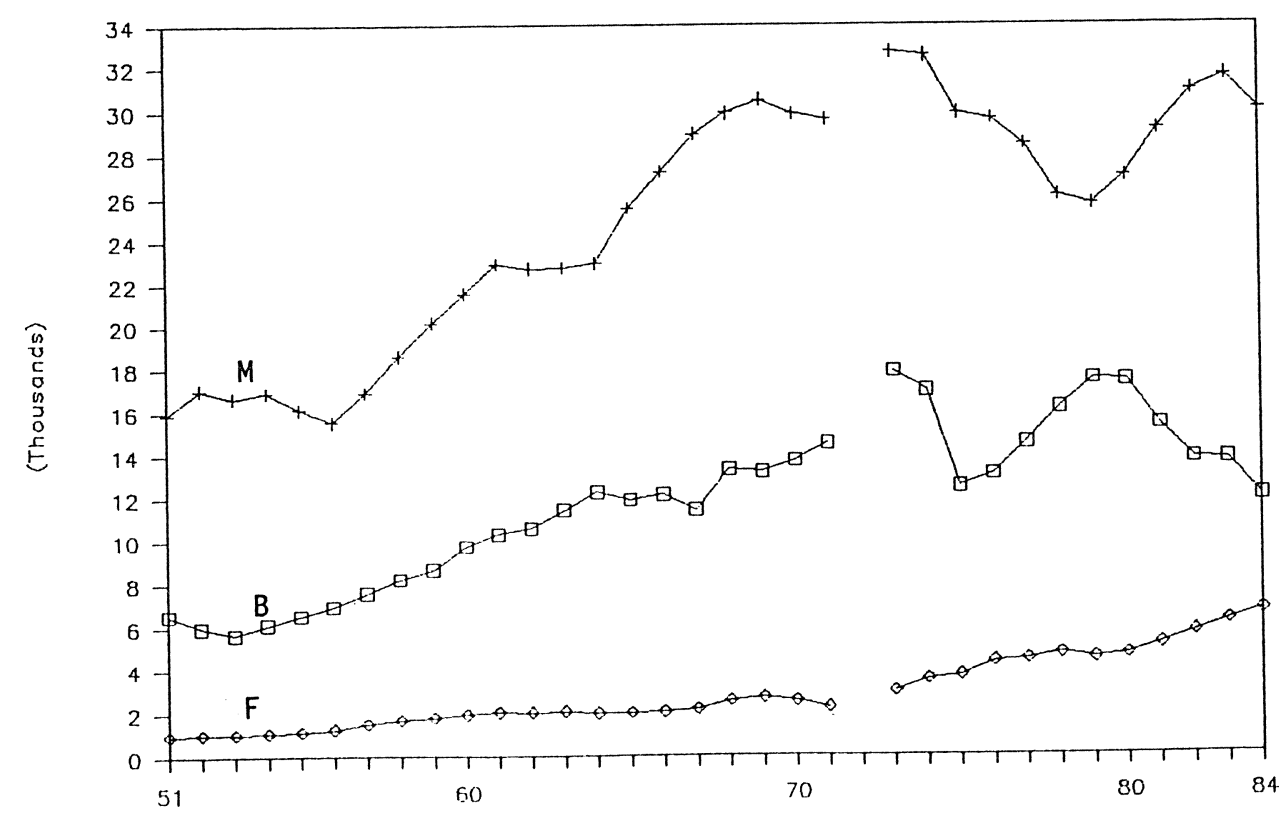

One main argument in the choice is excluded from the analysis. That is attending a specialisation in order to gain access to a higher type of education. Many schools have some kinds of entry requirements and a diploma of one of the three specialisations might meet such requirements. Although recently the number of students at junior secondary technical schools that continue their full-time education after their final exam is rather large, it is assumed that this argument does not play an important additional role in the choice of a specialisation. The first reason for this assumption is that it is likely that students defer their decision to continue education until the final exam is near. Another reason to neglect this point is that students will mostly continue education in the same type of specialisation, only on a higher level. The choice of a specialisation is still made at the same moment; in fact only the length of the course, and therefore the year they will enter the labour market, will be different.

The individual decision depends on preferences, capabilities and the labour market situation. Because preferences and capabilities are given for one student, they are constants in the choice-function of that individual student. The only variables in this individual choice-function are related

5. The enrollment in 1972 is missing due to the one year increase of the general curriculum in 1971 . 
to the labour market situation. Restricted by the availability of data, the labour market situation is only represented by the wages and the probabilities to get a job in the three specialisations. Because students do not know these figures exactly, the choice-function depends on their expectations of these figures rather than these figures themselves.

Due to the fact that a choice has to be made between only a few alternatives, the individual choice-function will be characterised by some switching points. Ceterus paribus a shift in a wage leads to a different choice at the moment the wage reaches this switching point. Because preferences are not equal for everyone, but distributed among the students, these switching points are also distributed among the students.

On an aggregated level this leads to a choice function in which the fraction of students choosing a certain specialisation increases as the expected labour market perspectives for that specialisation improve. The better these labour market expectations, the more students will have passed their switching point.

Assuming a certain distribution of preferences leads to a choice-function of the logit-form, e.g. for the ratio between the choice for the building industry specialisation and the metal industry specialisation:

$\frac{c_{B}}{c_{M}}=a_{1} \cdot\left(w_{B}^{e}\right)^{\pi 1} \cdot\left(p_{B}^{e}\right)^{\pi 2} \cdot\left(w_{M}^{e}\right)^{\pi 3} \cdot\left(p_{M}^{e}\right)^{\pi 4} \cdot\left(w_{F}^{e}\right)^{\pi 5} \cdot\left(p_{F}^{e}\right)^{\pi 6}$

in which $c_{j}$ is the number of students choosing specialisation $i(i=B, M, F)$, $w_{j}^{e}$ is the expected wage related to specialisation $i$ and

$p_{j}{ }_{i s}$ the expected probability to get a job, also for specialisation $i$.

By assuming that choices only depend on relative wages and relative probabilities (i.e. by assuming the 'income-effect' to be absent), equation (2.1) can be reduced to:

$\frac{c_{B}}{c_{M}}=a_{1} \cdot\left(\frac{w_{B}^{e}}{w_{M}^{e}}\right)^{\beta 11} \cdot\left(\frac{p_{B}^{e}}{p_{M}^{e}}\right)^{\tau 11} \cdot\left(\frac{w_{B}^{e}}{w_{F}^{e}}\right)^{\beta 12} \cdot\left(\frac{p_{B}^{e}}{p_{F}^{e}}\right)^{\tau 12}$ 
The other two equations are:

$$
\begin{aligned}
& \frac{c_{B}}{c_{F}}=a_{2} \cdot\left(\frac{w_{B}^{e}}{w_{F}^{e}}\right)^{\beta 21} \cdot\left(\frac{p_{B}^{e}}{p_{F}^{e}}\right)^{\tau 21} \cdot\left(\frac{w_{B}^{e}}{w_{M}^{e}}\right)^{\beta 22} \cdot\left(\frac{p_{B}^{e}}{p_{M}^{e}}\right)^{\tau 22} \\
& \frac{c_{M}}{c_{F}}=a_{3} \cdot\left(\frac{w_{M}^{e}}{w_{F}^{e}}\right)^{\beta 31} \cdot\left(\frac{p_{M}^{e}}{p_{F}^{e}}\right)^{\tau 31} \cdot\left(\frac{w_{M}^{e}}{w_{B}^{e}}\right)^{\beta 32} \cdot\left(\frac{p_{M}^{e}}{p_{B}^{e}}\right)^{\tau 32}
\end{aligned}
$$




\section{STUDENTS' EXPECTATIONS}

In section 2 a model of students' choices is developed in which the choices students make are a function of the expectations they have about the future labour market situation. In this section the model will be extended with two alternative hypotheses about the way in which expectations are formed.

In the economic literature with regard to students' choices, two streams of thought can be distinguished. The first stream is the so called cobweb theory, which assumes students to base their decisions entirely on the present instead of the future labour market situation. In other words, it is assumed that students expect the future situation to be similar to the present situation. This view is represented by Freeman (1975) and Fiorito and Dauffenbach (1982). Econometrically, this view is very attractive. Students' expectations are predetermined in this model, which makes estimation very easy. There are, however, some comments to be made about this assumption.

The cobweb theory implicitly assumes that all students have the same expectations about the future labour market situation. Empirical research, however, indicates that students' expectations can be strongly dispersed 6 . The cobweb theory could capture this shortcoming by assuming the expectations to be distributed with a mean that equals the present situation. But there is no reason to assume that equality will hold. Furthermore, students are considered too naive if it is assumed that they never anticipate future developments. It would at least be realistic to assume the probability to form an expectation in the right direction to be higher than an expectation in the wrong direction.

The second stream is represented by Zarkin (1983) and Siow (1984). In their models, students have rational expectations about the future labour market. The rational expectations theory assumes that students' expectations are the best possible expectations, given the data available at the moment choices have to be made. Again, this theory is contrary to the observation that expectations are dispersed, as the best prediction according to the rational expectations hypothesis will be the same for every student.

6. E.g. Kodde (1985), pp. 55-56. 
This objection could be removed by assuming students' expectations to be distributed round the best prediction. This assumption is not as ad hoc as the analogue assumption in the cobweb case. It could be possible that students all have different expectations, based on different believes about the 'true model', without knowing who has the best model. An error which would be made systematically by everyone every year, however, will be noticed and, therefore, avoided by the students.

There is, however, another objection against this assumption, which has been described in Borghans (1989). As soon as students know that their own predictions are not the best, additional information will be of value for them. The predictions of others are for example valuable information. This explains the interest in discussions among students about their choices, and, consequently, also the correlation between their expectations. A second source of information is the present labour market situation. By assuming that all the unmodelled factors are also present in the current situation, it is rational for students to adjust their expectations in a conservative direction if they are unsure about their expectations. Because this source of information is (except an error in the measurement) the same for everybody, students' expectations will be biased by the present situation. This leads to expected wages that lie between the present wages (i.e. the cobweb expectation) and the forecasted future wages (i.e. the rational expectation).

Summarizing, there are two extreme situations, the cobweb and the rational expectations theory. The cobweb theory assumes that students do not anticipate the future labour market situation and the rational expectation theory assumes that students anticipate the future situation as perfect as possible. These theories are extremes, so the truth might be somewhere in between. 


\section{THE ESTIMATION}

In order to investigate the use of information both the cobweb model and the rational expectations model will be estimated. 7 The next step will be the comparison of both models by a kind of encompassing method. It will be calculated to what extend one model is able to explain the unexplained part of the other model.

The first model to be estimated is the cobweb model. In the equations $(2.2),(2.3)$ and $(2.4)$ the expectation variables have to be replaced by present wages, which leads to e.g.:

$\frac{c_{B}^{t}}{c_{M}^{t}}=\alpha_{1} \cdot\left(\frac{w_{B}^{t}}{w_{M}^{t}}\right)^{\beta 11} \cdot\left(\frac{p_{B}^{t}}{p_{M}^{t}}\right)^{\tau 11} \cdot\left(\frac{w_{B}^{t}}{w_{F}^{t}}\right)^{\beta 12} \cdot\left(\frac{p_{B}^{t}}{p_{F}^{t}}\right)^{\tau 12}$

In which $t$ indicates the year.

In this model the choices are only influenced by predetermined quantities, so the use of ordinary least squares for the estimation is possible. To get a linear equation the logarithm is taken at both sides of the equations. In this model of three equations, in fact, two equations determine all the parameters of the third one. Due to the use of OLS these parameter restrictions between the three equations will be automatically fulfilled. Further, to allow for slow changes in preferences or the schooling system, a trend variable has been added.

The second model, with rational expectations, gives more estimation problems. According to McCallum (1976), future variables are taken as a proxy for expectations of these future variables:

$\frac{c_{B}^{t}}{c_{M}^{t}}=a_{1} \cdot\left(\frac{w_{B}^{t+d}}{w_{M}^{t}+d}\right)^{\beta 11} \cdot\left(\frac{p_{B}^{t+d}}{p_{M}^{t}+d}\right)^{\tau 11} \cdot\left(\frac{w_{B}^{t+d}}{w_{F}^{t}+d}\right)^{\beta 12} \cdot\left(\frac{p_{B}^{t+d}}{p_{F}^{t}+d}\right)^{\tau 12}$

In which $t$ represents the year and $d$ the number of years between the moment of choice and the entrance onto the labour market.

7. The models will be estimated separately and not in one model in which both theories are nested, because the estimation of such a nested model leads to some identification problems in case of a small sample size. 
Because rational expectations are by definition the best possible expectations, the difference between these expectations and their realisations can not be correlated with the expectations, so there has to be a correlation between this error-term and the proxy-variable. Furthermore, if the lag between the moment of choice and the entrance onto the labour market (d) is more than one year, the error-terms will be autocorrelated, because the periods of prediction are overlapping. Thus, the error term in this model is both autocorrelated and correlated with the 'exogenous' proxy-variables. Using OLS in such a situation would lead to an estimation that is biased because of the correlation with the 'exogenous' variables and not efficient because of the autocorrelation. Cumby, Huizinga and Obstfeld (1983) suggest an estimator for such models (a two-step twostages least squares estimator), which is both efficient and unbiased. The model is estimated with lagged variables as instruments for the endogenous variables that are correlated with the error term and this estimation is carried out twice, a first step assuming no autocorrelation and a second step using autocorrelation estimates taken from the first step. A disadvantage of this procedure is that the parameter restrictions between the three equations will not be fulfilled automatically anymore.

At last, the encompassing experiment will be performed. Because it would be unfair to compare a model estimated with OLS, with a model not estimated with OLS, the rational expectation model is re-estimated with OLS for this purpose. OLS is the estimator that provides the best fit, so the results of another estimator will at best lead to an equal fit.

The encompassing is performed by the estimation of for example the next equation:

$\frac{c_{B}}{c_{M}}=\lambda \cdot\left(\frac{\hat{c_{B}}}{\frac{\hat{c}_{M}}{c_{M}}}\right)+(1-\lambda) \cdot\left(\frac{\hat{c}_{B}^{R E}}{\frac{c_{M}^{R E}}{c_{M}}}\right)$

Or in words:

real data $=\lambda *$ prediction cobweb $+(1-\lambda) *$ prediction rat exp

If the cobweb model is strictly better than the rational expectations model (i.e. the rational expectation predictions equal the cobweb predictions except for some noise not correlated with the real data) a will be equal to 1. The other extreme is a equals 0 . In this case the rational expectation 
$-13-$

model dominates the cobweb model. The absolute t-values indicate the additional information of the model, compared with the other model. 


\section{ESTIMATION RESULTS}

Table 1 presents the estimation results of the cobweb model. It contains six 'triangles'. Each triangle shows the effects of a change in wages or the probability to get a job (vertically) in one of the three sectors (horizontally), leaving all other variables constant. For example, if the probability to get a job in the building industry (first triangle of the second row) increases by $1 \%$, the ratio of students choosing building industry specialisation and students choosing the metal industry specialisation increases by $2.72 \%$. Significant effects (The level of significance is $90 \%$, which corresponds to an absolute t-value greater than 1.703) are indicated by a bold arrow.

Table 1: Estimation with Cobweb model

(absolute $t$-values between brackets)

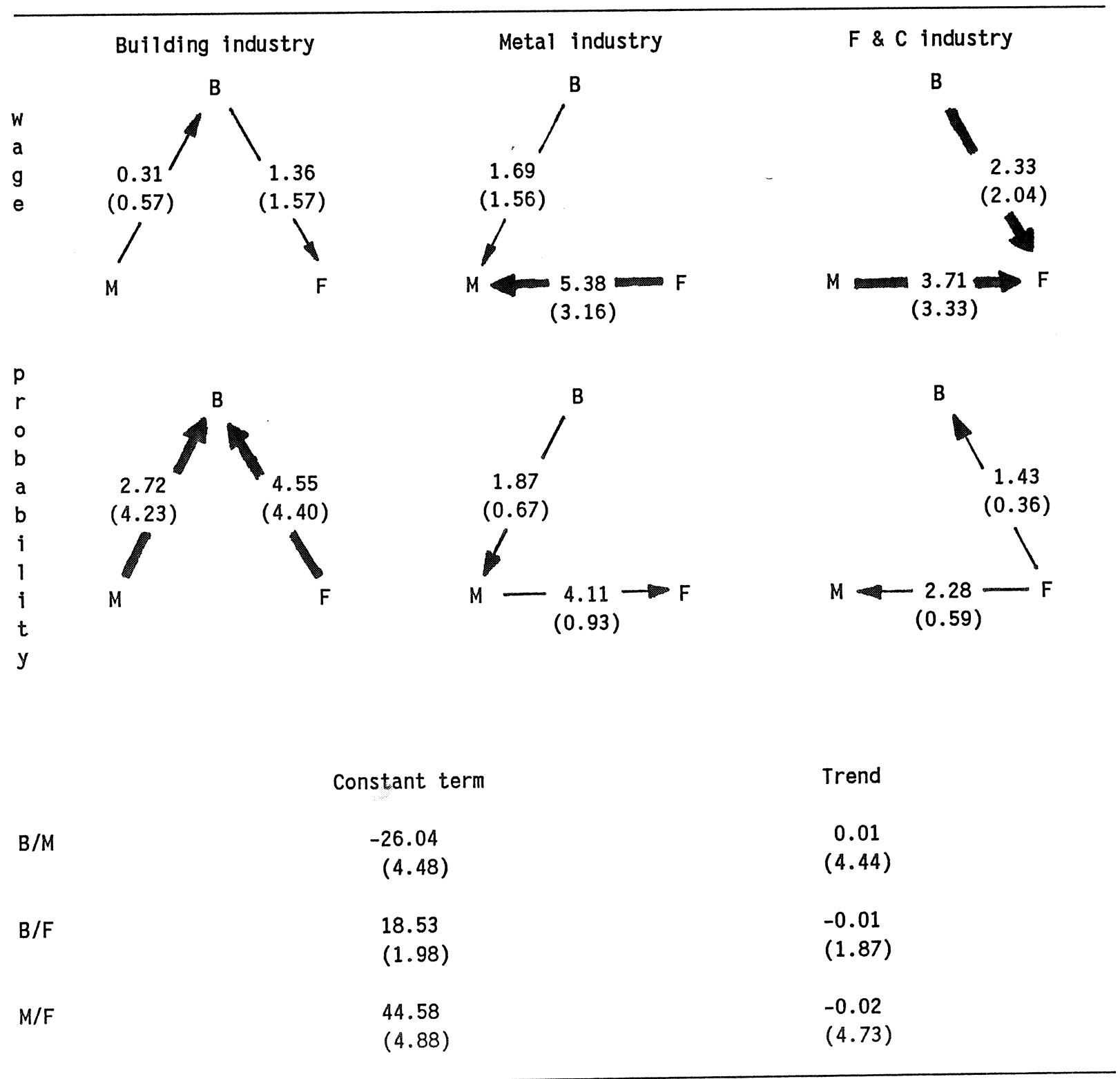


All significant effects do have the correct sign. The significant arrows suggest that probabilities play an important role for the choice for the building industry specialisation, while wages are most important for metal industry and food and catering. The insignificance of the other parameters might be caused by the fact that these effects are rather sma11, or by the fact that the cobweb assumption about the expectations does not hold.

Since it is difficult to interpret the parameters of table 1 , an example of the size of these results is presented in table 2. In order to indicate the trend the predicted choices of 1951 and 1984 have been calculated as if no wages and probability differences occurred. Furthermore, the table presents the predicted choices in 1984, based on actual wages and probability figures, and the changes in this distribution in case of a $1 \%$ change of one of the six labour market variables.

Table 2: An example of the estimation results of the cobweb model (significant effects have been printed bold)

\begin{tabular}{lccc}
\hline & B & M & F \\
& & & 1707 \\
1951 (all wages and prob. equal) & 7079 & 14628 & 5891 \\
1984 (al1 wages and prob. equal) & 18286 & 24623 & 5952 \\
1984 (actual wages and prob.) & 13330 & 29518 & \\
change due to 1\% rise of & & & +82 \\
wage B & +2 & -84 & -247 \\
wage M & -79 & 326 & +173 \\
wage F & +73 & -246 & -137 \\
probability B & +293 & -156 & +248 \\
probability M & -247 & -1 & -104 \\
probability F & -46 & +149 & \\
& & &
\end{tabular}

Table 2 shows that the growth of the food and catering specialisation is structural. The growth is not only caused by an increase in wages or probabilities to get a job, but from 1951 to 1984 this specialisation grew $300 \%$, even with no differences in wages and probability. 
Table 3: Estimation of the rational expectations model (absolute $t$-values between brackets)

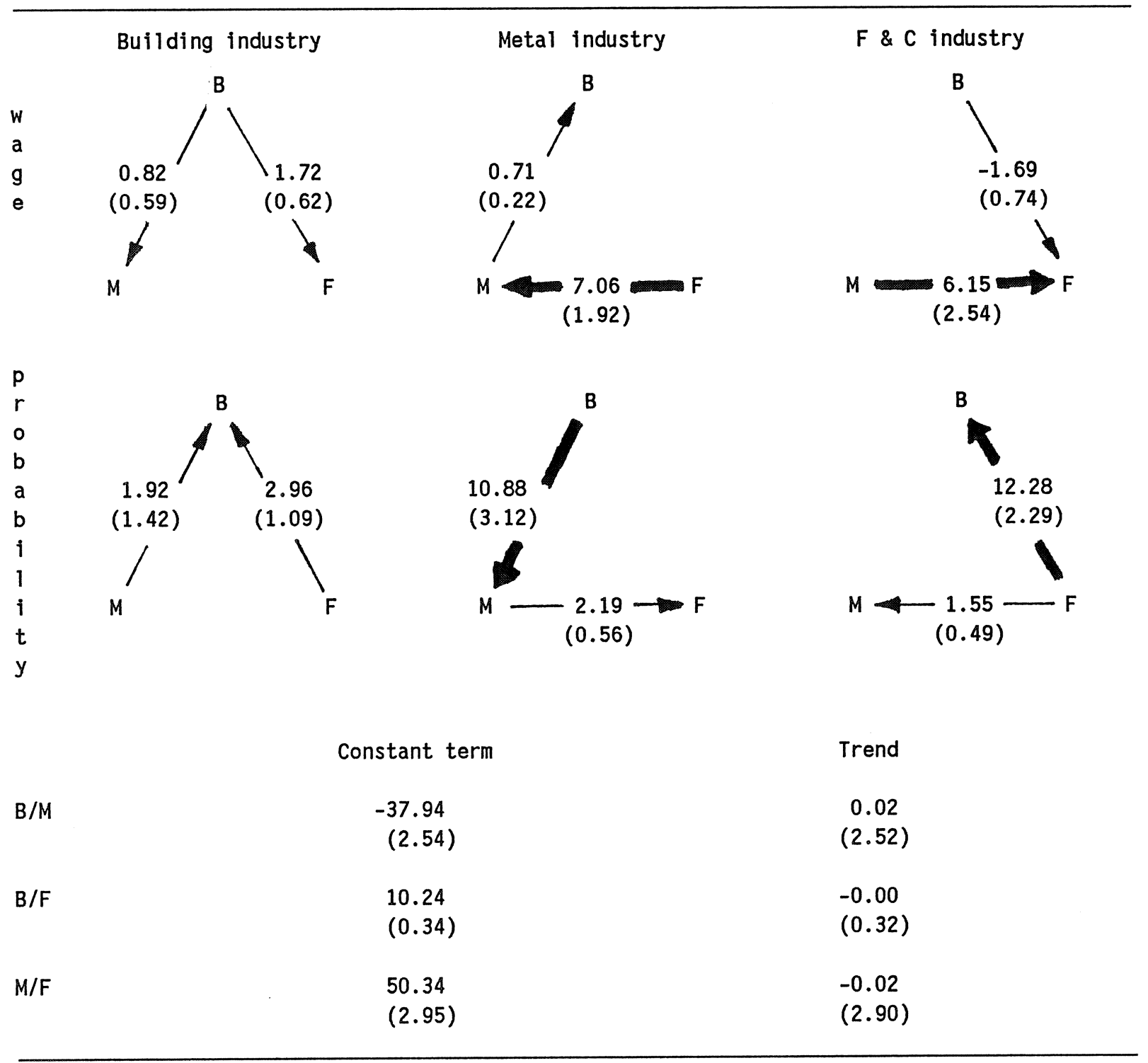

In 1984, the labour market situation caused 4956 students to leave the building industry in favour of mainly the metal specialisation.

Table 3 shows the estimation results of the rational expectations model. The results are rather poor. Four out of the twelve labour market effects are significant and one of these, the ratio between building and food and catering industry, has the wrong sign.

Table 4 gives an example of the rational expectations estimation results, similar to table 2. As parameter restrictions in the rational expectations are not fulfilled, the parameters of the third equation, the ratio of the choices for metal industry and food and catering industry, have been taken 
according to the other two equations. The table shows more clearly the disappointing estimation results.

Three possible explanations might be given for these bad estimation results of the rational expectations model. The first interpretation is that the rational expectations model is completely wrong. The second, that the influence of anticipated wages and probabilities is rather small compared to present wages and probabilities, and because of this the estimator is not able to construct significant effects with the amount of data available. A third explanation for the poor results is the possibility that the use of realized wages as a proxy for rational expectations is not good enough.

Table 4: An example of the estimation results of the rational expectations model (significant effects have been printed bold)

\begin{tabular}{lccc}
\hline & B & M & F \\
& & & \\
1951 (all wages and prob. equal) & 5560 & 15754 & 2100 \\
1984 (all wages and prob. equal) & 16486 & 25030 & 7284 \\
1984 (actual wages and prob.) & 14702 & 28743 & 5355 \\
change due to 1\% rise of & & & \\
wage B & -98 & +42 & +56 \\
wage M & +182 & +152 & -334 \\
wage F & -90 & -205 & +295 \\
probability B & +214 & -137 & -80 \\
probability M & -1156 & +770 & +387 \\
probability F & +985 & -687 & -298 \\
& & & \\
\hline
\end{tabular}

In figure II and III the fit of two models has been indicated. They show the percentage of students in a certain year that did not choose the specialisation which was predicted by the model. Although, due to the different estimation techniques a comparison between the cobweb-model and the rational expectations model is not completely justified, it is obvious that the rational expectations model fits less well than the cobweb model. It is, however, impossible to draw final conclusions out of this observation. 
Figure II: Misspecification of the cobweb model

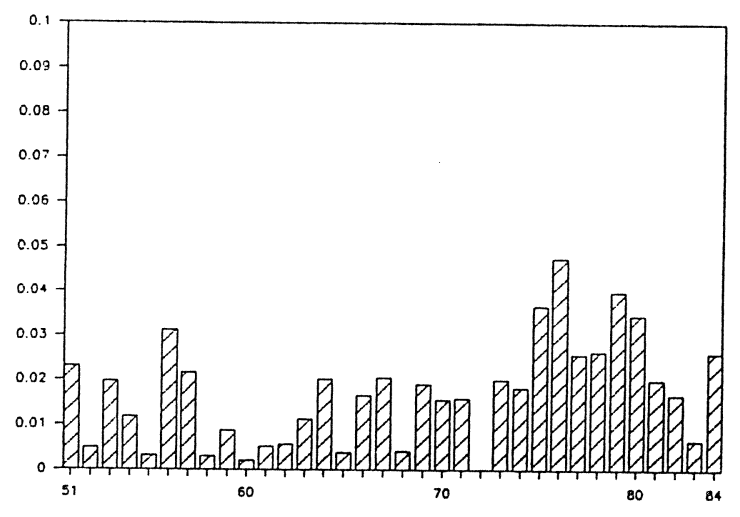

Figure III: Misspecification of the rational expectations model

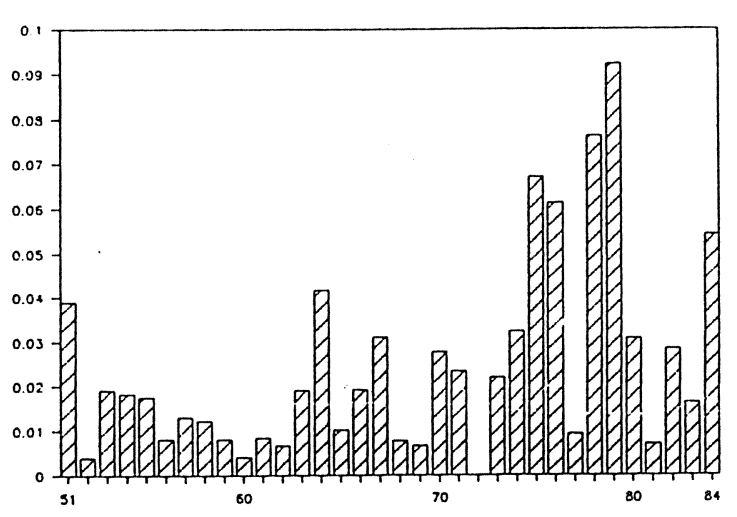

In order to get an indication of the influence of both hypothesis, the two extreme models will be compared. Zarkin (1983) mentions the difficulties of comparing these two models. A comparison of the R-squared will not suffice because of the correlation of the explanatory variables of both models. However, an encompassing procedure enables us to make such a comparison.

Table 5 gives the results of this encompassing experiment. The parameter $\lambda$ has been estimated for the three equations of the model, but also seperately for the three equations only containing wages as explaining variables, and for the equations with only probabilities to get a job as explaining variables. If the predictions of both the cobweb model and the rational expectation model are regressed on the real data, e.g. in the complete model of the building industry versus food and catering, the cobweb predictions get a parameter value of 0.64 and the rational expectation model 0.36 . If a parameter of this kind gets 1 and therefore the other parameter 0 , the mode 1 with the 1-parameter explains at least everything that is explained by the other mode1. The 0 -parameter model might be rather good, but it is dominated by the other model.

The table shows that in most cases the cobweb model has a higher parameter value than the rational expectations model, but the hypothesis that all rational expectations parameters equal 0 will be rejected. 
Table 5: The encompassing experiment

real data $=\lambda$ * prediction cobweb $+(1-\lambda) *$ prediction rational expectations

( $t$-value between brackets)

\begin{tabular}{|c|c|c|c|c|c|c|}
\hline & \multicolumn{2}{|c|}{ Both } & \multicolumn{2}{|c|}{ Wage } & \multicolumn{2}{|c|}{ Probability } \\
\hline & Cob & RE & Cob & RE & Cob & RE \\
\hline & $\lambda$ & $1-\lambda$ & $\lambda$ & $1-\lambda$ & $\lambda$ & $1-\lambda$ \\
\hline \multirow[t]{2}{*}{$\mathrm{B} / \mathrm{M}$} & 0.67 & 0.33 & 0.79 & 0.21 & 0.70 & 0.30 \\
\hline & $(3.84)$ & $(1.87)$ & $(1.53)$ & $(0.41)$ & $(3.33)$ & $(1.44)$ \\
\hline \multirow[t]{2}{*}{$B / F$} & 0.64 & 0.36 & 0.63 & 0.37 & 0.68 & 0.32 \\
\hline & $(2.89)$ & $(1.63)$ & $(1.37)$ & $(0.81)$ & $(2.45)$ & (1.14) \\
\hline \multirow[t]{2}{*}{$M / F$} & 0.42 & 0.58 & 0.54 & 0.45 & 0.00 & 1.00 \\
\hline & $(1.71)$ & $(2.36)$ & $(1.75)$ & $(1.48)$ & $(0.00)$ & $(1.52)$ \\
\hline
\end{tabular}

An overall conclusion of the analysis of this section might be that in general the cobweb model gives better estimation results, but the rational expectations model is still able to explain part of the remaining error of the cobweb model. 


\section{IMPLICATIONS}

In section 2 the information problem of students choosing their vocational specialisation at junior secondary technical schools has been set out. For two reasons it is difficult for students to base their decisions on correct information. Firstly, because of the time-lag between the choice of specialisation and the labour market entry. Secondly, because of the fact that markets are not fully cleared by wages. In this section the extent of this problem will be indicated by use of the estimation results of section 5.

In order to be able to indicate the extent of the problem, a criterion for measurement is needed. The criterion used here is the amount of students that (according to the estimated supply function) would have chosen another specialisation if they had had full information on future labour market prospects. Three observations have to be made about this criterion. Firstly, it measures only aggregated, net effects. If one student chooses the metal instead of the building industry, but another student chooses the building instead of the metal industry these effects will not appear in the aggregated supply functions of the previous sections. Secondly, the criterion does not take into account the fact that if everybody had chosen the right specialisation, the labour market situation would have been different. Finally, the criterion gives every mismatch equal weight, while there will be some students who made a wrong decision, who were almost indifferent between the 'right' and the 'wrong' decision, while others' costs of a wrong decision might be rather high. In general, this will lead to an overestimation of small mismatches and an underestimation of large mismatches.

On account of the results of the estimation in the last section, the assumption is made that the cobweb model is the correct model. Thus, students' choices are completely determined by the present labour market situation. The extent of the mismatch is measured, based on the estimations of the cobweb model.

Figure IV shows the fraction of students that made the wrong decision, per year. The amount of students making a wrong decision is, especially in recent years, rather high: on average $3 \%$ of all the students at the junior secondary technical schools, but the last ten years on average $7 \%$, up to almost $16 \%$ in 1984 . 
Figure IV: The total mismatch

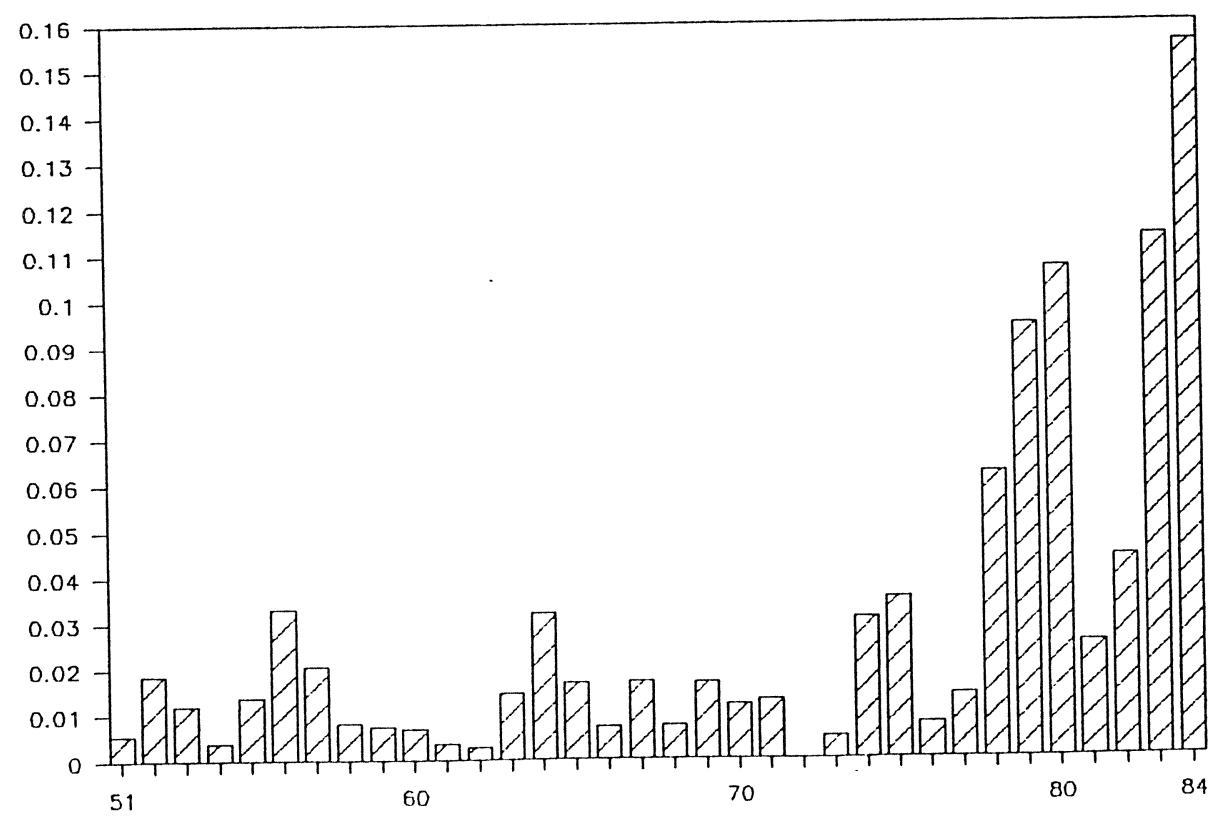

Figures V, VI and VII provide the same data for the three specialisations separately. All the three specialisations show an increase in recent years; in the building industry, however, the change is most radical. In the food and catering specialisation some high percentages of mismatch already occur in the fifties.

The extent of the problem is far from equal for the three specialisations. In the building industry the fraction making the 'wrong' decision is $9 \%$ on average and goes up to $49 \%$ in 1980 , while the average in the metal industry is $4 \%$ with a maximum of $22 \%$ in 1984 . The food and catering specialisation also has its maximum in 1984 , at $60 \%$, but in this sector high scores already appeared in the fifties, with e.g. $27 \%$ in 1956 . In this sector the average mismatch is $12 \%$.

Figure V: Mismatch in the building industry

Figure VI: Mismatch in the metal industry
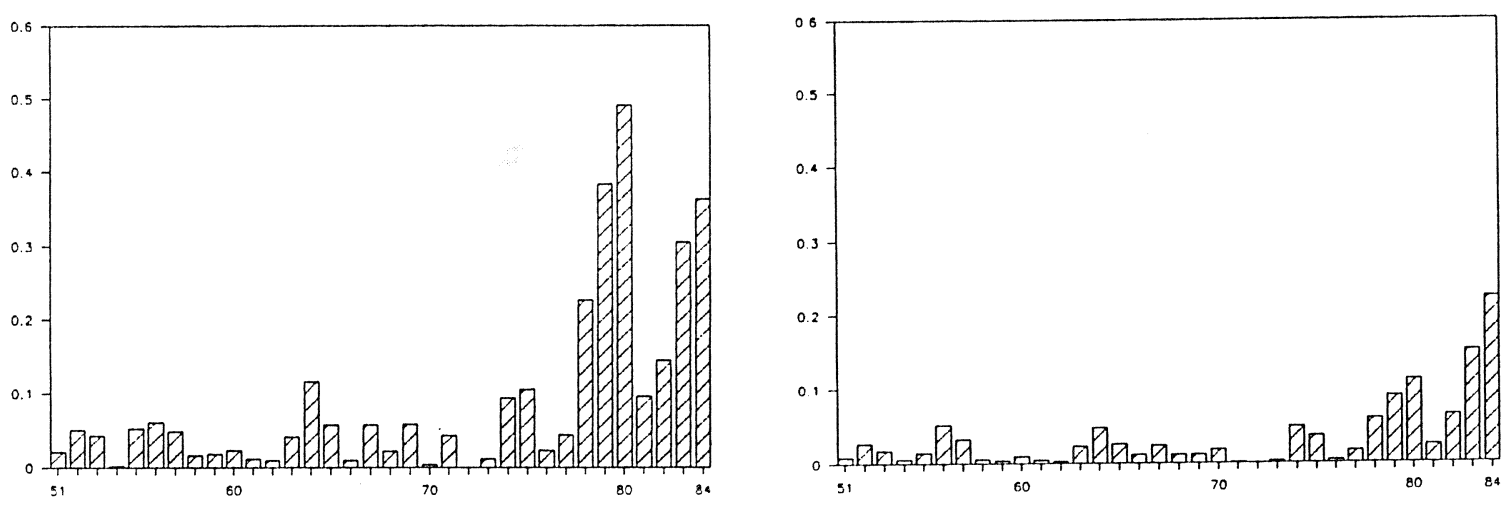
Figure VII: Mismatch in food and catering

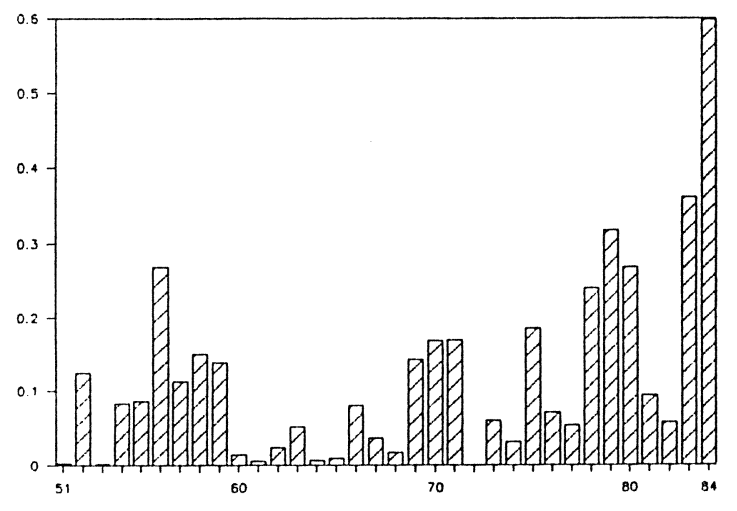

The mismatch fractions indicated in these figures might be seen as an indication for the value of correct information. If correct information was available this fraction of students would have chosen correctly, and thus this amount of students would be better off in that case.

In figure VIII and IX this value of information is split up into information about the wages and information about the probability to get a job. The figures lead to two important conclusions. Firstly, the value of information about the wages is decreasing while the value of information about probabilities to get a job is increasing. Secondly, while the value of information about wages is only $0.9 \%$ on average before 1972 and $0.4 \%$ after 1972 , the value of information about the probability to get a job is $0.9 \%$ on average before 1972 but $5.7 \%$ after 1972 .

Figure VIII: Value of information about wages

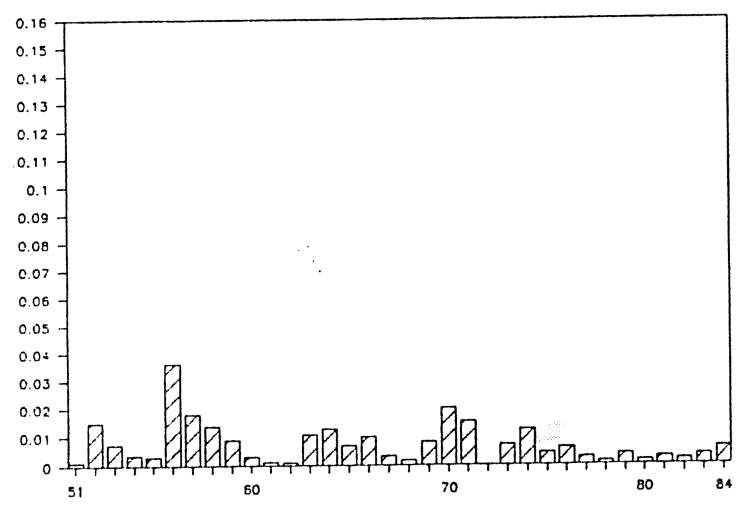

Figure IX: Value of information about the probability to get a job

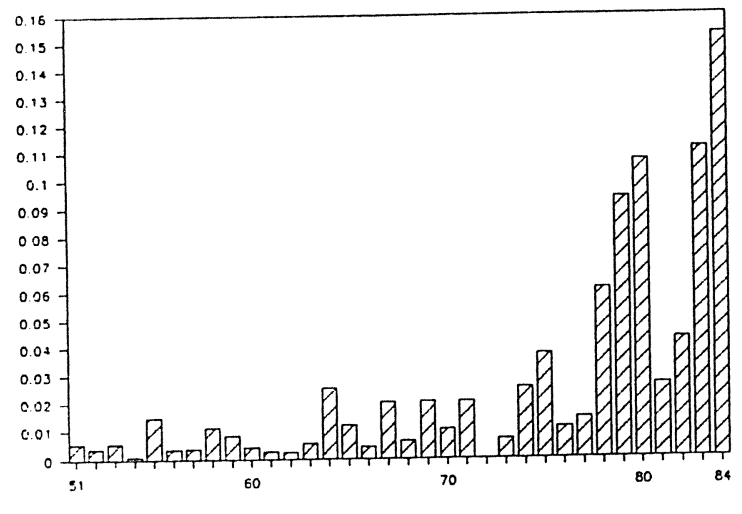

The decrease of the value of information about wages might be explained by the increase of the wage-rigidity. If wages do not change much the value of knowing future wages instead of present wages is not big, because present wages will be a good predictor for future wages. But, due to this wage- 
rigidity the fluctuations of the probability to get a job have risen. If wages do not regulate the allocation process anymore, this task will be adopted by the unemployment rate. The increase of the total mismatch might have two alternative explanations. Firstly, it might be the case that an allocation process performed by unemployment rates is more costly than an allocation process performed by wages, from an information point of view. Secondly, labour market fluctuations might have increased in recent years, so the total costs also increased. 


\section{CONCLUSIONS}

The aim of this paper has been to investigate the information problem which students are faced with when making a choice between alternative vocational specialisations. The first question we raised was: does the labour market situation play a role in the choice of a specialisation? Mainly the estimation results of the cobweb model, showed that indeed there seems to be an influence of both wages and probability to get a job on students' choices. Table 2 shows that about 10\% of the students in 1984 made a choice that differed from the notional choice in a situation in which no wages and probability differences occurred. The estimations indicate that the probability to get a job is rather impotant for the building industry, while the wages are a more important factor in the choice for the metal industry and the food and catering specialisation.

The second question was: do students anticipate future situation or do they only take the present situation as a criterion for the future? We tried to answer this question by introducing two extreme models: the cobweb model and the rational expectations model. Both models have been estimated and a comparison has been made by means of an encompassing experiment. It is, however, difficult to draw clear conclusions from these tests. Most statistics seem to indicate a better performance of the cobweb model, but none of these indicators is able to reject the rational expectations hypothesis.

Finally we investigated the extent of the information problem, assuming that the cobweb model is the true model. The mismatch due to the information time-lag in this model goes up to $16 \%$ in 1984 . The building industry specialisation and the food and catering specialisation are most affected by this problem. By providing good predictions about the future labour market situation these mismatches might be remedied. Another interesting conclusion is that the value of additional information about the future wages is decreasing through time, while the value of information about the probability to get a job is becoming more and more important in recent years. 
APPENDIX: THE DATA

The data used for estimation has been based on five sources:

(a) The numbers of students present in the first year of specialisation at the Dutch LTS and ITO have been taken from The Statistics of the Junior Secondary Vocational Education (Statistiek van het lager beroepsonderwijs) 8 , for the years 1964 till 1984 except 1972 (because of the change in the length of the general curriculum from 1 to 2 years). The figures have been aggregated into the three groups building industry (B), metal industry (M) and food and catering industry (C) according to:

$B$ : building technique except furniture making and upholster

fitting technique (esp. heating systems)

$M$ : mechanical technique

electrical engineering

motor vehicle technique

diesel engine assembly

$F$ : food and catering industry technique

(b) The numbers of students leaving the Dutch LTS or ITO with a diploma have been taken from The Statistics of the Junior Secondary Vocational Education (Statistiek van het lager beroepsonderwijs) for the years 1949 till 1986. The figures have been aggregated into the same groups as (a).

(c) The numbers of unemployed registered at the Labour-exchange according to occupational group/occupation in the months January, April, July and October have been taken from Monthly Bulletin of Socio-Economic Statistics (Sociaal-economische maandstatistiek), for the years 1953 till 1986. They have been classified according to:

B: construction workers

fitters (esp. heating systems)

plumbers

M: metal workers except fitters and plumbers

$F$ : food and stimulant industry workers

hotel and catering workers

8. All publication used for data are published by Netherlands Central Bureau of Statistics (C.B.S.). Publications of the C.B.S. are mentioned by their present name. The names of these publications have been slightly different in the past. 
A few observations were missing. They have been estimated by interpolation with season correction.

(d) figures about paid employment by kind of economic activity have been taken from National Accounts (Nationale jaarrekeningen), for the years 1949 till 1986. Classification according to:

$B$ : building industry

$M:$ metal industry

$F$ : food and stimulant industry hotel and catering industry

(e) Figures about compensation of employees by kind of economic activity have been taken from National Accounts (Nationale jaarrekeningen), for the years 1949 till 1986. Classification is similar to (d).

By use of these five sources three variables have been constructed:

(A) The choice for one of the three specialisations is taken from (a) for the years 1964 till 1983. For the previous years this figure has been predicted by estimating the relationship between the choice (a) and the number of students leaving with a diploma for the years both sources were available, and imposing this relationship on the previous years.

(B) The wages per worker in the three groups is calculated by dividing (e) by $(d)$.

(c) The probability to get a job is defined as the quotient between (d) and (d) plus the number of unemployed. The number of unemployed for a certain year is the mean of the number of unemployed in the four months distinguished in (c). The missing years, 1949 till 1952 have been taken as being equal to 1953 . 
Table 6: The data

\begin{tabular}{|c|c|c|c|c|c|c|c|c|c|}
\hline \multirow[t]{2}{*}{ year } & \multicolumn{3}{|c|}{ choices } & \multicolumn{3}{|c|}{ wages } & \multicolumn{3}{|c|}{ prob. to get a job } \\
\hline & B & $M$ & $F$ & B & M & $F$ & B & M & $F$ \\
\hline 1949 & & & & 2852 & 3651 & 2633 & 0.9634 & 0.9770 & 0.9724 \\
\hline 1950 & & & & 2953 & 3232 & 2809 & 0.9634 & 0.9770 & 0.9724 \\
\hline 1951 & 6555 & 15913 & 946 & 3268 & 3553 & 3032 & 0.9634 & 0.9770 & 0.9724 \\
\hline 1952 & 5972 & 17061 & 1003 & 3461 & 3841 & 3184 & 0.9634 & 0.9770 & 0.9724 \\
\hline 1953 & 5645 & 16671 & 1003 & 3684 & 3878 & 3287 & 0.9634 & 0.9770 & 0.9724 \\
\hline 1954 & 6138 & 16917 & 1052 & 3820 & 4230 & 3656 & 0.9739 & 0.9890 & 0.9796 \\
\hline 1955 & 6545 & 16139 & 1135 & 4037 & 4548 & 4009 & 0.9816 & 0.9934 & 0.9874 \\
\hline 1956 & 6991 & 15551 & 1242 & 4320 & 5032 & 4371 & 0.9897 & 0.9967 & 0.9937 \\
\hline 1957 & 7601 & 16918 & 1490 & 4959 & 5487 & 4848 & 0.9842 & 0.9950 & 0.9930 \\
\hline 1958 & 8230 & 18633 & 1661 & 5167 & 5691 & 5346 & 0.9566 & 0.9784 & 0.9862 \\
\hline 1959 & 8699 & 20207 & 1748 & 5270 & 5890 & 5465 & 0.9711 & 0.9877 & 0.9867 \\
\hline 1960 & 9754 & 21562 & 1909 & 5659 & 6449 & 5914 & 0.9837 & 0.9957 & 0.9904 \\
\hline 1961 & 10332 & 22898 & 2027 & 5975 & 7101 & 6563 & 0.9895 & 0.9971 & 0.9928 \\
\hline 1962 & 10600 & 22715 & 2015 & 6333 & 7451 & 6948 & 0.9936 & 0.9971 & 0.9921 \\
\hline 1963 & 11457 & 22724 & 2065 & 6843 & 8186 & 7601 & 0.9925 & 0.9964 & 0.9917 \\
\hline 1964 & 12290 & 22944 & 1961 & 8116 & 9383 & 8715 & 0.9933 & 0.9968 & 0.9917 \\
\hline 1965 & 11915 & 25511 & 1995 & 8923 & 10569 & 9530 & 0.9896 & 0.9966 & 0.9907 \\
\hline 1966 & 12184 & 27207 & 2029 & 10002 & 11670 & 10537 & 0.9840 & 0.9958 & 0.9908 \\
\hline 1967 & 11454 & 28963 & 2165 & 11106 & 12954 & 11430 & 0.9492 & 0.9868 & 0.9867 \\
\hline 1968 & 13318 & 29952 & 2528 & 12562 & 14066 & 12241 & 0.9632 & 0.9868 & 0.9843 \\
\hline 1969 & 13213 & 30521 & 2675 & 14017 & 15178 & 13051 & 0.9829 & 0.9916 & 0.9837 \\
\hline 1970 & 13715 & 29920 & 2510 & 15803 & 17200 & 14902 & 0.9854 & 0.9938 & 0.9849 \\
\hline 1971 & 14517 & 29623 & 2222 & 18412 & 19417 & 16893 & 0.9786 & 0.9906 & 0.9851 \\
\hline 1972 & & & & 20667 & 21509 & 19290 & 0.9484 & 0.9763 & 0.9788 \\
\hline 1973 & 17863 & 32716 & 2954 & 23838 & 24971 & 22455 & 0.9547 & 0.9776 & 0.9753 \\
\hline 1974 & 16958 & 32547 & 3493 & 27389 & 29041 & 26078 & 0.9330 & 0.9772 & 0.9758 \\
\hline 1975 & 12519 & 29924 & 3695 & 30810 & 32355 & 29584 & 0.9080 & 0.9617 & 0.9641 \\
\hline 1976 & 13065 & 29636 & 4332 & 33607 & 35761 & 33069 & 0.9304 & 0.9530 & 0.9572 \\
\hline 1977 & 14515 & 28448 & 4423 & 37207 & 38810 & 35078 & 0.9474 & 0.9581 & 0.9588 \\
\hline 1978 & 16131 & 26076 & 4673 & 39786 & 41676 & 37832 & 0.9600 & 0.9677 & 0.9688 \\
\hline 1979 & 17463 & 25654 & 4464 & 41053 & 44224 & 40176 & 0.9613 & 0.9691 & 0.9576 \\
\hline 1980 & 17405 & 26953 & 4636 & 45428 & 46752 & 42088 & 0.9339 & 0.9676 & 0.9549 \\
\hline 1981 & 15365 & 29131 & 5111 & 47398 & 49145 & 44305 & 0.8555 & 0.9377 & 0.9352 \\
\hline 1982 & 13775 & 30950 & 5686 & 50708 & 52827 & 47637 & 0.7824 & 0.8979 & 0.9301 \\
\hline 1983 & 13728 & 31607 & 6220 & 52786 & 54753 & 49640 & 0.7097 & 0.8230 & 0.8288 \\
\hline 1984 & 12053 & 30070 & 6677 & 52773 & 55537 & 50455 & 0.7191 & 0.8206 & 0.8101 \\
\hline 1985 & & & & 52305 & 56230 & 51948 & 0.7622 & 0.8446 & 0.8075 \\
\hline 1986 & & & & 53660 & 57485 & 53240 & 0.8636 & 0.8978 & 0.8520 \\
\hline
\end{tabular}


Figure $X$ : The wages (relative to their mean)

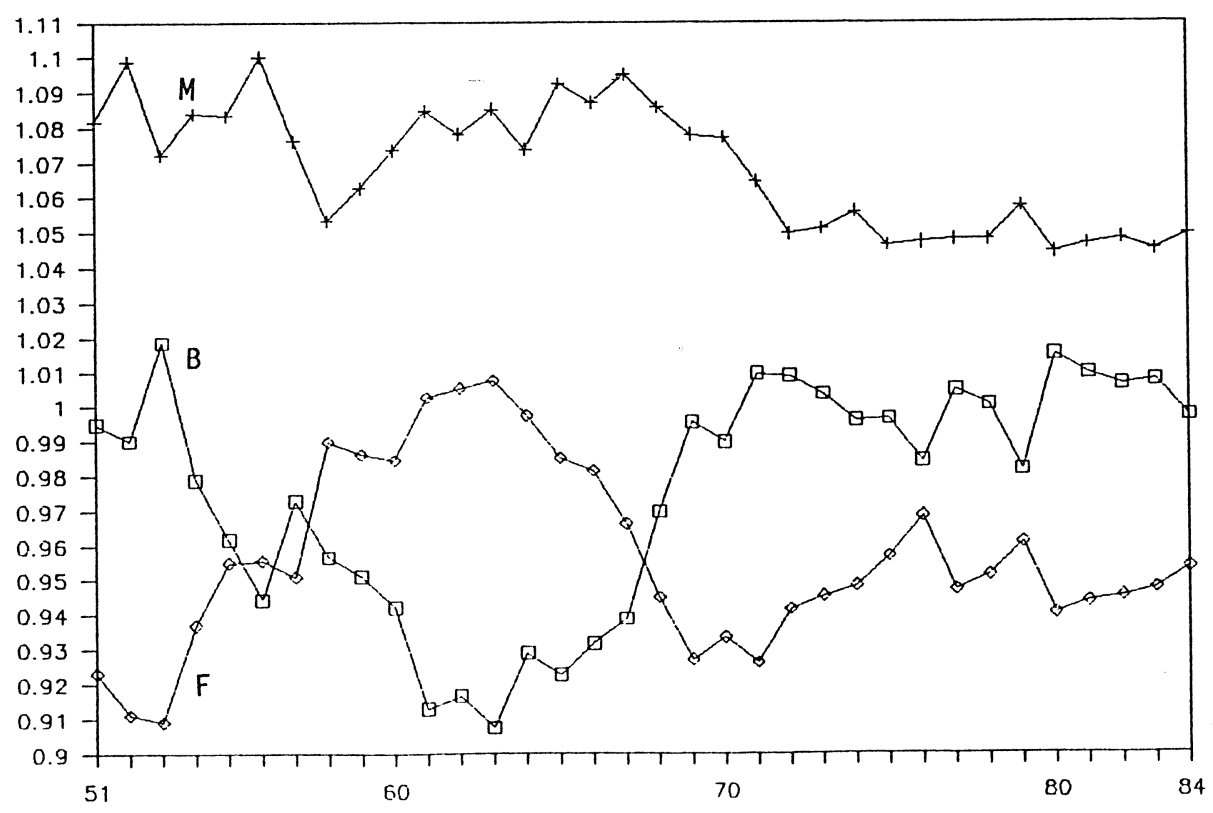

Figure XI: The probabilities to get a job

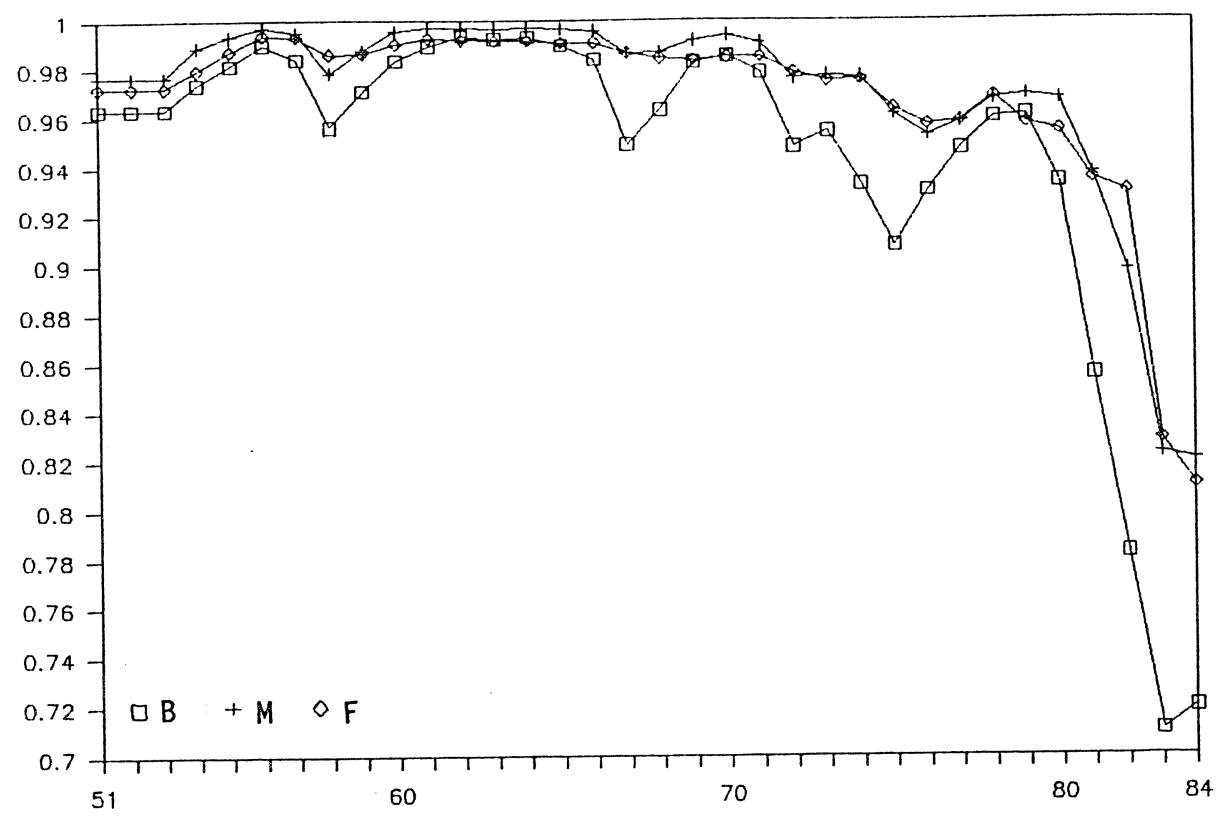




\section{REFERENCES}

Borghans, L., Information and the Choice for Schooling. Research Centre for Education and Labour Market, ROA-W-1989/1E, Maastricht, 1989.

Cumby, R. E., J. Huizinga and M. Obstfeld, 'Two-Step Two-Stage Least Squares Estimation in Models with Rational Expectations'. Journal of Econometrics 21 (1983), pp. 333-355.

Fiorito, J. and Dauffenbach, R.C., 'Market and Nonmarket Influences on Curriculum Choice by College Students'. Industrial and Labor Relations Review 36 (1982), pp. 88-101.

Freeman, R.B., 'Legal "Cobwebs": A Recursive Model of the Market for New Lawyers'. Review of Economics and Statistics 57 (1975), pp. 171-179.

Freeman, R.B., 'Employment Opportunities in the Doctorate Manpower Market'. Industrial and Labor Relations Review 33 (1980), pp. 185-197.

Hayek, F., 'The Use of Knowledge in Society'. American Economic Review 35 (1945), pp. 519-553.

Kodde, D.A., Microeconomic Analysis of Demand for Education. Rotterdam, 1985.

McCallum, B.T., 'Rational Expectations and the Estimation of Econometric Models: An Alternative Procedure'. International Economic Review 17 $(1976)$, pp. 484-490.

Siow, A., 'Occupational Choice under Uncertainty'. Econometrica 52 (1984), pp. 631-645.

Zarkin, G.A., 'Cobweb versus Rational Expectations Models'. Economics Letters 13 (1983), pp. 87-95.

Zarkin, G.A., 'Occupational Choice: An Application to the Market for Public School Teachers'. Quarterly Journal of Economics 100 (1985), pp. 409-446. 